\title{
El Real santuario de la Virgen de la Fuente de Salud de Traiguera
}

\author{
Concepción González Hernández
}

\section{Historia}

El real santuario de Nuestra Señora de la Fuente de la Salud (figura 1) está ubicado en un valle a $3 \mathrm{~km}$ de Traiguera, al norte de la provincia de Castellón.

El conjunto arquitectónico es un lugar de encuentro, remanso de paz, belleza y armonía, donde se puede encontrar una representación de varios estilos artísticos: desde el gótico (siglo xv), pasando por el renacentista, el barroco, el neoclásico y la arquitectura popular del Maestrazgo, hasta la actualidad.

Según cuenta la historia, entre los siglos XIII-XIV en el valle existía un pozo (figura 2, en la actualidad) y los pastores y ganaderos se abastecían de

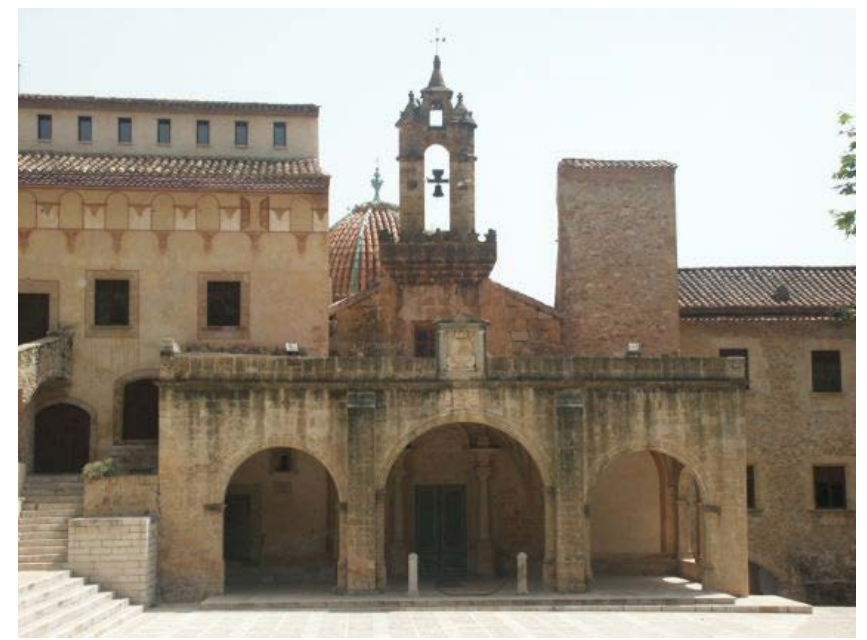

Figura 1. Real Santuario de la Fuente de la Salud de Traiguera él. En ese lugar, en el año 1384 (aunque existen controversias con las fechas del milagro), tuvo lugar el hallazgo milagroso de la Virgen a dos pastores de Cervera del Maestre. La leyenda popular lo describe así:

Dos pastores hermanos de poca edad (Anastasio y Jaime Sorlí, mudo de nacimiento) guardaban las cabras los vecinos de Cervera. Pero las jornadas de trabajo por los montes eran muy largas y, a menudo, los hermanos padecían sed. Un día, Jaime vio una cabra con las barbas mojadas de agua. Se adentró en el bosque, por donde salía la cabra, y encontró una fuentecilla de donde manaba un poco de agua. Bebió de ella, alzó los ojos, y vio a la Mare de Deu; seguidamente le dio gracias y comenzó a hablar.

Se dirigieron a la villa de Traiguera a comunicar lo sucedido a las autoridades y vecinos. Volvieron al

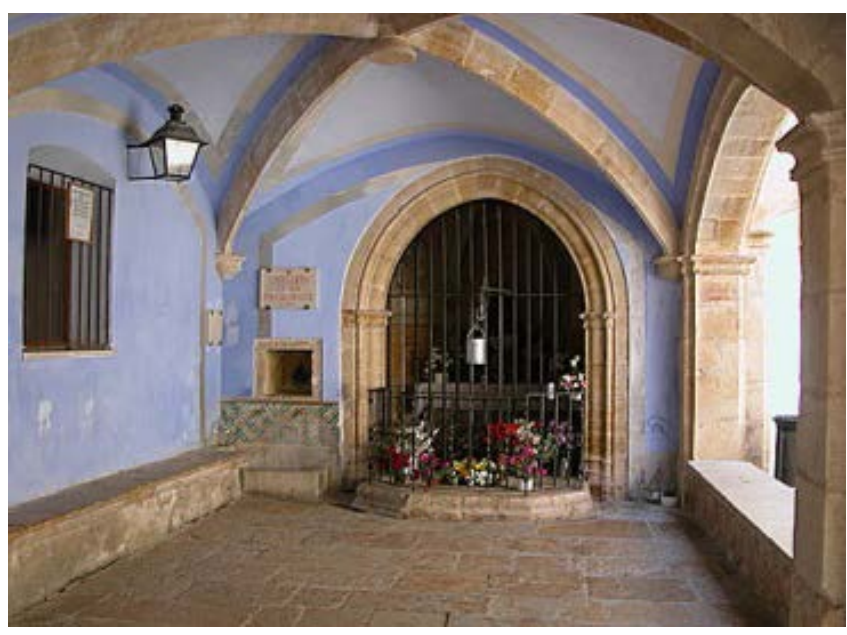

Figura 2. Lugar donde se apareció la Virgen 


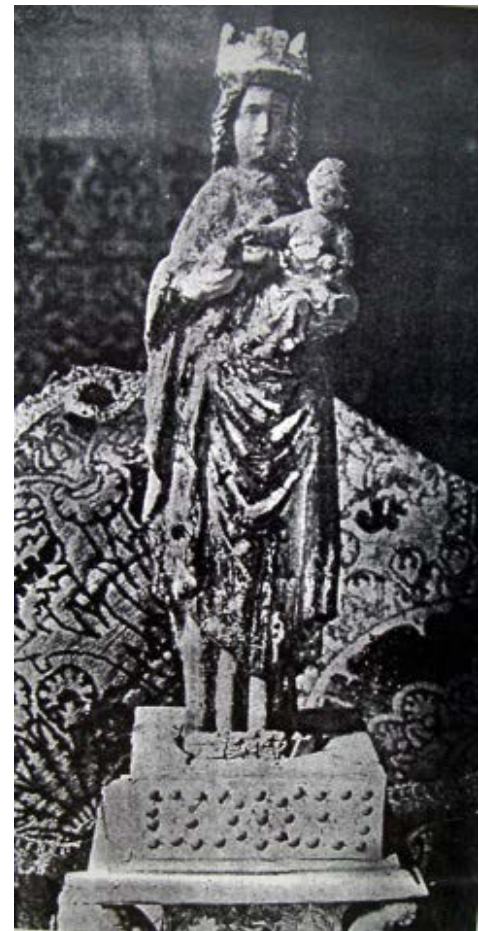

Figura 3. Mare de Déu original, ya desaparecida

lugar, cogieron la imagen que había en la fuentecilla y la llevaron a la iglesia parroquial. Al día siguiente, cuando regresaron a la parroquia, la imagen había desaparecido y la volvieron a encontrar en la fuentecilla.

A raíz del hallazgo, construyeron un templo rural, muy sencillo, con un techo de madera que duró 55 años. La virgen que lo presidía (figura 3 ) era una talla de madera de unos 0,47 centímetros de altura, de estilo gótico, vaciada en su reverso y con soportes de madera para poder ser llevada a mano o colgada del cuello. Representaba a la Virgen de pie llevando sobre el brazo izquierdo al Niño. Madre e hijo mostraban en la mano una manzana. Este templo estaba donde se encuentra ahora el pozo y la pequeña capilla de la fuente (figura 2).

Las villas de Traiguera y la de Cervera mantuvieron disputas por la ermita. Los pastores y el rebaño eran de Cervera, pero el término municipal donde se encontraba la virgen pertenecía a Traiguera. Finalmente, Traiguera salió victoriosa de esta disputa, aunque los vecinos de Cervera del Maestrat siempre han tenido el derecho de visitarla un día al año. Además, también han podido participar de una parte civil administrativa gestionada por

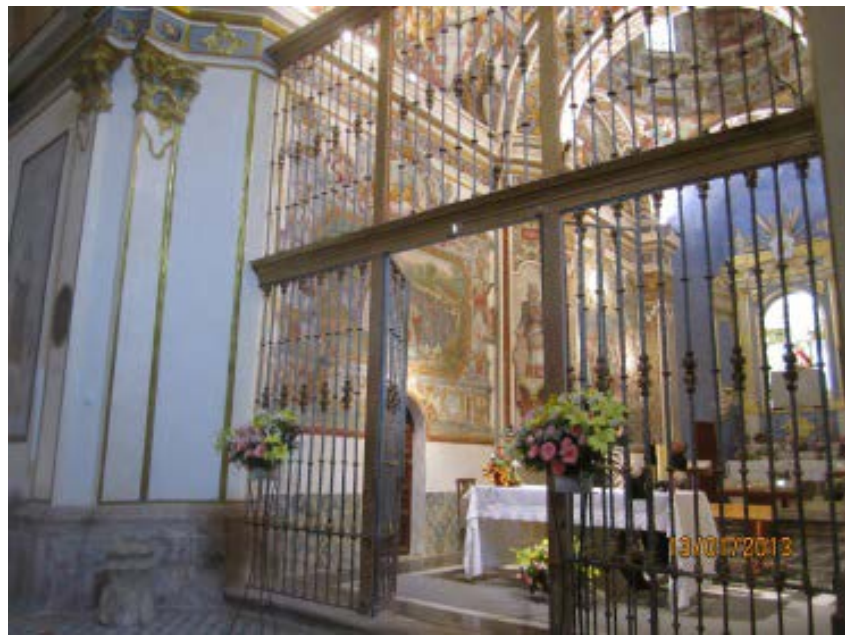

Figura 4. Verja de hierro del tempo

el Consejo Municipal de Traiguera y otra religiosa gestionada por la parroquia.

Con el gran desarrollo demográfico que se produjo entre finales del siglo XIV y principios del XV, tuvieron que construir un templo gótico con una campana y un retablo con la imagen hallada en el valle. La primera piedra para la construcción la colocó el maestre de la Orden de Montesa. La planta del templo iba desde la puerta actual hasta el crucero (donde está la verja de hierro, figura 4).

En 1542, Carlos I otorgó un privilegio al ermitorio de real santuario, como se puede comprobar gracias a símbolos que lo constatan como las cadenas de la entrada del pórtico. El pórtico que está formado por tres crujías de planta cuadrada, cubiertas con bóvedas de crucería; la central lleva terceletes $y$ en cada una de las claves secundarias hay ins-

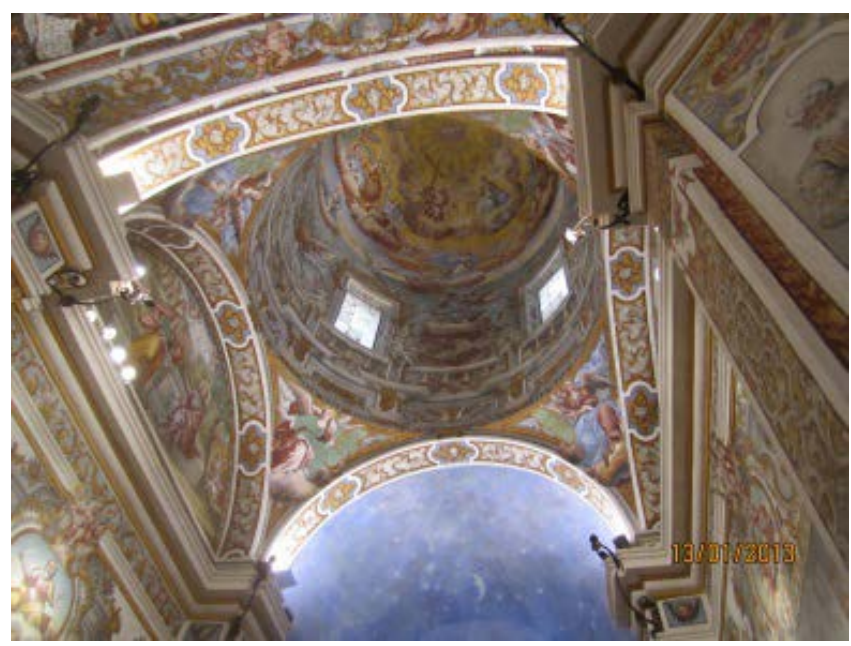

Figura 5. Cúpula del tempo 


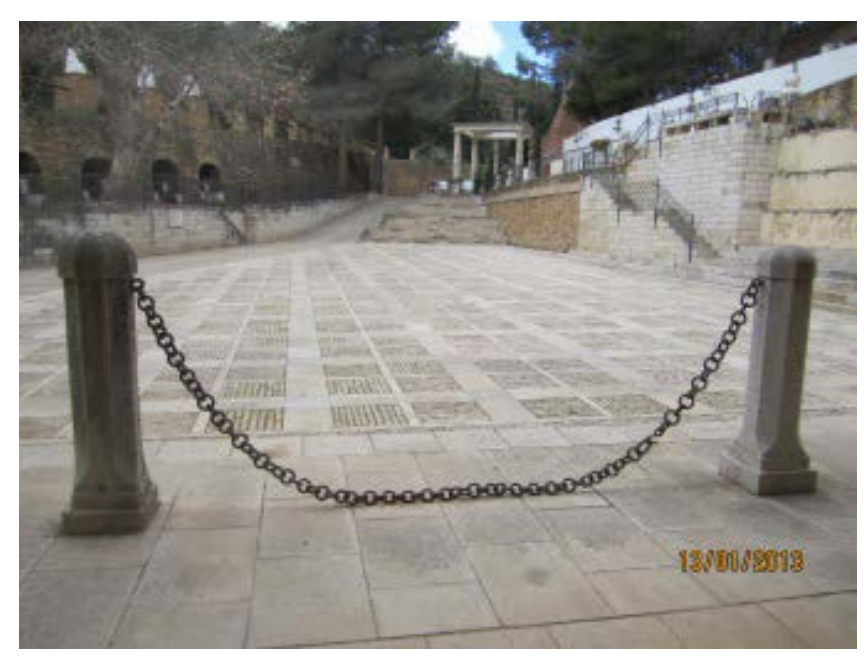

Figura 6. Cadenas de entrada

cripciones de números que nos indican el año de su construcción: 1588. Este santuario fue visitado por ilustres personalidades como Felipe II, quien lo hizo en dos ocasiones, siendo un gran promotor y protector del mismo, Felipe IV, Cervantes y otras muchas personalidades.

Entre 1531-1536 se construyó la hospedería con habitaciones para acoger a los peregrinos; debajo de ella, la primera ermita medieval. También se construyó un hospital entre los años 1590-1595 para atender a los peregrinos enfermos. El edificio del actual restaurante Casa de los Capellanes era el claustro que se construyó en 1570 para albergar la capellanía y, delante del mismo, podemos ver lo que empezó a construirse de lo que iba a ser el palacio de los duques de Segorbe (figura 7), que no llegó a terminarse por la enemistad con los Borgia.

Desde el s. XVI, los Borgia habían visitado con frecuencia el ermitorio, habían aportado dinero y tenían una gran influencia en el lugar. Alfonso de Aragón, el duque de Segorbe, también visitó con frecuencia el ermitorio. Quiso construirse su palacio, pero la enemistad con los Borgia, mucho más influyentes que él, fue, como hemos apuntado, la causa de que las obras no concluyesen.

Luego entró en una época decadencia por la crisis del Antiguo Régimen en nuestro país y en la mayor parte de Europa. Posteriormente, volvió a resurgir $\mathrm{y}$, en 1707, comenzaron las obras del nuevo templo gótico con añadidos renacentistas y barrocos. Del crucero hasta el altar se edificó de nuevo. Hicieron otra cúpula, convirtiéndose en camerino separado

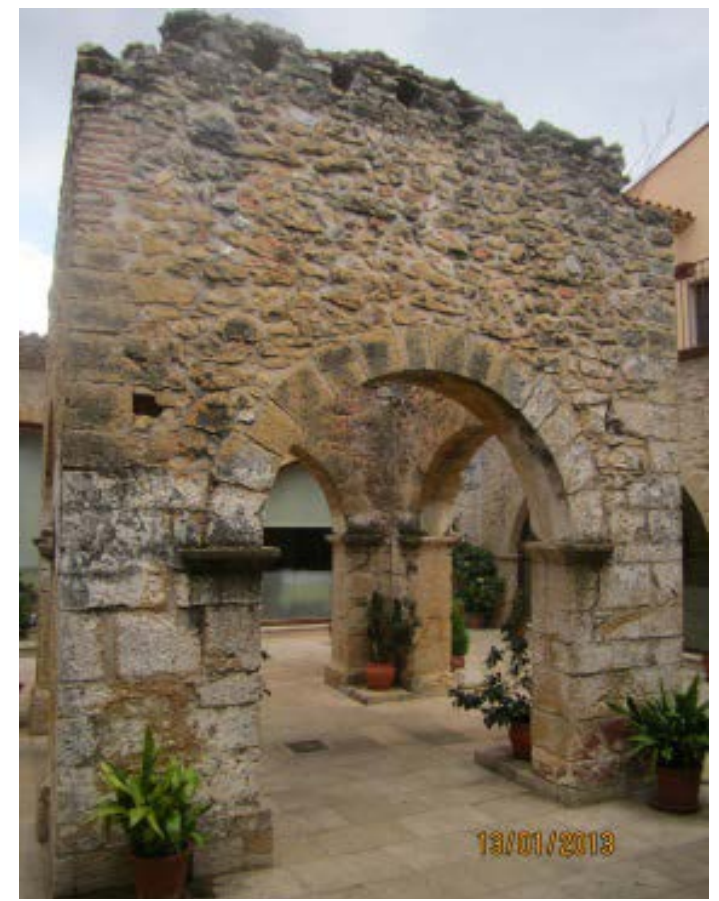

Figura 7. Restos del palacio del duque de Segorbe

del resto del templo por una reja decorada, finalizando las obras en 1716.

La decoración está hecha con símbolos marianos, por su dedicación a la Virgen. Las pinturas murales se realizaron en 1736 .

Partiendo desde Traiguera hasta la ermita, existían siete peirones que representaban los siete dolores de la Virgen, que señalaban, al mismo tiempo, la importancia del camino. El último peirón era el más grande y estaba cubierto, anunciando, de esta manera, a los peregrinos que ya habían llegado al santuario. Actualmente, solo hay cuatro restaurados por la escuela taller; el último quedó restaurado, pero descubierto.

Desde el año 1986 hasta el 2000, la ermita y su entorno fueron restaurados por la escuela taller en dos fases. Este lugar participó en la exposición de La Luz y las Imágenes en el año 2006.

\section{Romerías}

Desde finales del siglo xix se recuerda en el pueblo de Traiguera que, en la ermita de la Fuente de la Salud, hubo ermitaños hasta finales del siglo xx. Tradicionalmente, se hacían unas romerías a la Fira de la Mare de Déu donde acudían los pueblos vecinos. 
Se celebraban pasada la semana de Pascua, entre los meses de abril y mayo. Una tradición antigua que no existe en otros ermitorios de alrededor. Actualmente, continúa haciéndose, aunque cada uno de ellos tiene una fecha determinada, siendo el primero de ellos el de La Jana.

La Jana: este pueblo vecino se encuentra a unos $4 \mathrm{~km}$ de distancia de Traiguera. Antiguamente, solían celebrar el día de la romería pasando por dentro del pueblo con sus carros, para dirigirse a la ermita. Al coincidir con la Pascua, los niños se ponían a verlos pasar y se comían la tradicional mona mientras los romeros les tiraban peladillas. La fecha depende de cómo caiga la Pascua, siendo originalmente los martes de Pascua, aunque actualmente lo celebran el lunes de Pascua.

Traiguera: celebra la romería el día conocido como sábado carnal. En la actualidad, se celebra el domingo siguiente de Pascua.

San Jorge: era una pedanía de Traiguera conocida como el Mas dels Esteller hasta que, en 1261, se segregaron. Este pueblo vecino la celebra el día 1 de mayo y, desde hace unos años, hacen unas calderas populares. Aunque el día original es el 3 de mayo, fiesta de la Sta. Cruz.

Canet lo Roig: se celebra el primer domingo de mayo; antiguamente era la fiesta conocida como el siete de mayo.

San Rafael del Rio: celebra su romería el penúltimo domingo del mes de mayo. También era una pedanía de Traiguera. La separación se produjo más recientemente, en el año 1927.

Cervera del Maestre: el último domingo de mayo se oficia una misa en el santuario, se hace un concierto a cargo de la Banda Unión Musical Sta. Cecilia, una comida de hermandad y una verbena popular.

Benicarló: celebra su romería el primer domingo del mes de octubre. Antiguamente, los desplazamientos se hacían en carros. Salían de Benicarló la víspera y se alojaban en la hospedería. Por la mañana, tocaban diana y, a continuación, hacían una procesión y se rezaba el rosario. Esta tradición la continúa realizando la cofradía de los rosarieros y la peña Setrill.

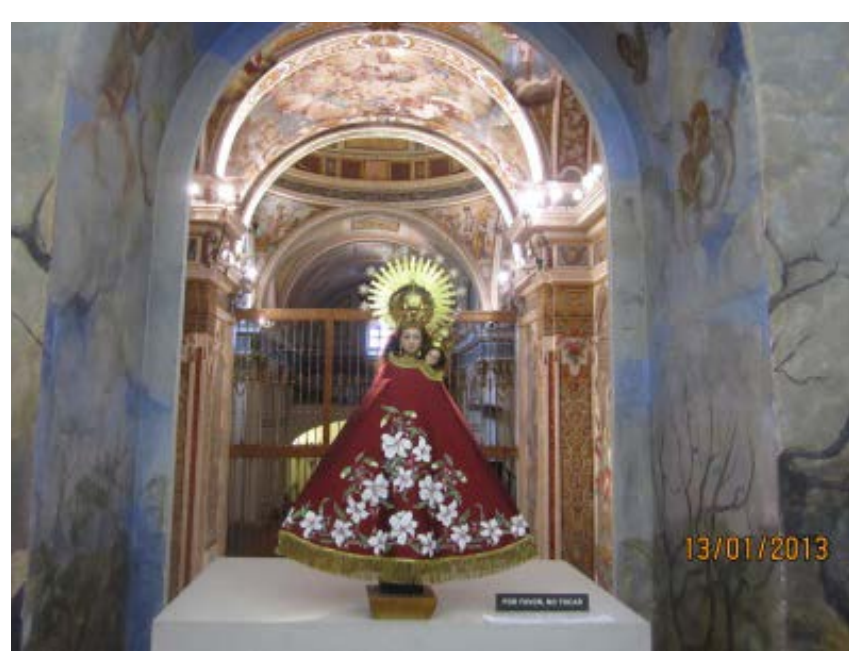

Figura 8. Imágen de la Mare de Déu

Traiguera: la fiesta principal de la Mare de Déu, siempre se ha celebrado el día 8 de septiembre. En la actualidad, se celebra el primer domingo de septiembre. Este año 2013 se celebrará de nuevo el día 8 por coincidir en domingo.

Antiguamente, acudían los vecinos en carros a la ermita a pasar el día. Los más jóvenes iban a pie con canastos de mimbre transportando la comida para prepararla y las collas se distribuían alrededor de la ermita buscando la sombra de los árboles. También solían alquilar por un día las habitaciones típicas de la parte de la hospedería. Allí, se preparaban las paellas o el guisado de conejo y la carne torrada hecha con las brasas que quedaban. De postre, se degustaban los pastisets y el brazo de gitano que se elaboraba la víspera. Era toda una tradición para el pueblo, una fiesta tan importante y a la que acudía tanta gente que los bares y tabernas del pueblo se trasladaban provisionalmente por un día para abastecer de bebidas y refrescos a los asistentes.

Ese día también acudían lugareños de los pueblos de la comarca vecina, hasta de Tarragona. Es por eso que se conocía popularmente como la Fira dels Catalans y, por ello, se cantaban canciones típicas en referencia a los visitantes como:

A la Font de la Salut,

hi ha una ermita molt guapeta,

que allí van els catalans

a gastar-se la pesseta.

Marieta fes-te el monyo, que ton pare hi ha vingut, 
i t'ha dut una pinteta

de la Font de la Salut.

\section{Procesión del septenio}

El plano pastoral diocesano, con motivo del año jubilar 2000, quiso reavivar las tradiciones religiosas y populares de los pueblos. Este se lo comunicó al consejo parroquial de Traiguera en el mes de septiembre de 1999 y surgió la idea de organizar una procesión y trasladar por primera vez a la Mare de Déu desde la ermita al pueblo de Traiguera y, una vez allí, se haría una novena. Hasta el mes de enero estuvieron madurando la idea. Entonces tomaron la decisión de comunicárselo a la Cofradia de la Mare de Déu de la Font de la Salut, quienes acogieron la idea con gran satisfacción. Lo hicieron público el día de la feria en la ermita.

Con motivo del año jubilar, como se había acordado, por primera vez se celebró la procesión llevando la imagen a hombros por la gente del pueblo, en su mayoría mujeres.

Una vez estuvo la imagen en el pueblo, se programó un recorrido dividiendo el pueblo en dos sectores, para hacer dos procesiones y que la Mare de Déu visitara a un total de 29 enfermos que lo habían solicitado con anterioridad. El día 2 de septiembre por la tarde volvieron a hacer una procesión hasta la ermita para que la imagen de la Virgen estuviera allí el 8 de septiembre, día de la feria.

A partir de esta primera vez, por decisión del pueblo y consensuado por el consejo parroquial a propuesta de mosén Juan José Roca, se acordó que cada siete años se volvería a hacer la procesión.

En el año 2007 se volvió a celebrar, el día 24 de agosto. Primero con una misa en el ermitorio oficiada por el obispo de la diócesis de Tortosa, monseñor Xavier Salinas, el rector de Traiguera, mosén Julián Escude, y el anterior rector del pueblo y promotor mosén Juan José Roca. Además, también asistieron mosén Ferrán, arcipreste y rector de Morella, mosén Membrado, vicario episcopal, mosén Florencio y el hermano Claudio Esteller, hijo de Traiguera. Cuando acabó la misa, partió la procesión con la imagen hacia Traiguera y regresó al cumplirse la novena el día 2 de septiembre.

En el año 2014 se volverá a celebrar el tercer septenio.

\section{Referencias}

Ferreres, J. (2009) L’esplendorosa Traiguera renaixentista, Antinea. Vinaròs, Castellón.

Ferreres, J. y Llatje, D. (1992). La Font de la Salut. Ed. Pàrroquia de l’Assumpció de Traiguera. Benicarló, Castellón. 